\title{
O pensamento anti-racialista brasileiro no inicio do século XX: Manoel Bomfim e Alberto Torres
}

\author{
Jéssica Maria Rosa Lucion
}

O pensamento anti-racialista brasileiro no inicio do século XX: Manoel Bomfim e Alberto Torres

Resumo: O pensamento de Manoel Bomfim e Alberto Torres entra para o cenário nacional, principalmente, pela originalidade ao tratar o "Brasil-Problema" desconectando-se dos seus contemporâneos ao refletir o país pelo viés sócio-histórico e não racialista. Suas ideias soam como dissidentes numa época onde prevalece o racismo científico e a preocupação das elites concentrava-se na miscigenação, a mistura entre raças superiores e evoluídas (europeus) e raças inferiores e atrasadas (índios e negros). Destas preocupações surgiram análises sobre a realidade brasileira que, mais tarde, foram incorporadas à constituição de políticas de branqueamento no país. O presente artigo traz uma reflexão sobre a obra dos autores em questão evidenciando suas análises sobre o Brasil e as soluções que propõem para a situação do país ao buscarem contribuir para a formação do "Brasil-Nação".

Palavras-Chave: Manoel Bomfim. Alberto Torres. Anti-racialismo. Brasil-Nação.

The Brazilian anti-racialist thought in the early twentieth century: Manoel Bomfim e Alberto Torres

Abstract: The thought of Manoel Bomfim and Alberto Torres enters the national scene, mainly for originality in addressing the "Brazil-Problem" disconnecting themselves from their contemporaries to reflect the country bias by socio-historical and non-racialist. His ideas sound like dissidents in a time where scientific racism and the concern of elites concentrated on mixing, mixing between upper and evolved races (Europeans) and inferior races and delayed (Indians and blacks) prevails. Analysis of these concerns arose about the Brazilian reality, later, the establishment of policies bleaching in the country were incorporated. This paper presents a reflection on the work of the authors in question evidencing their analysis about Brazil and the solutions they propose for the country's situation to seek help for the formation of the "BrazilNation".

Key-Words: Manoel Bomfim. Alberto Torres. Anti-racialism. Brazil-Nation.

Esta obra foi licenciada sob uma Licença Creative Commons - Atribuição 3.0 Não Adaptada. 


\section{Introdução}

Na passagem do século XIX para o XX, a elite brasileira estava preocupada com os rumos do país. Apegada aos pressupostos do positivismo e do evolucionismo, enxergava a população brasileira enquanto degenerada, inviável para o progresso e desenvolvimento, um entrave para a desejada modernização do país. Neste sentido, fazia uso da explicação racial para tratar os problemas brasileiros, ou seja, baseava-se nos pressupostos do chamado "racismo científico". Tal corrente de pensamento e análise tem como bases principais as obras de Spencer, Darwin e Conde Gobineau. No Brasil o racismo científico direciona suas lentes para a questão da miscigenação já que esta chamava mais as atenções dos que estavam preocupados com a viabilidade do país: a mistura entre raças superiores e evoluídas (europeus) e raças inferiores e atrasadas (índios e negros), para alguns, gerava a degeneração, enquanto outros a positivavam. Positivar a miscigenação, no entanto, não era uma forma de análise comum, a maioria estava realmente preocupada com os malefícios que ela poderia causar.

Merece destaque que tais concepções serviram para a justificação da situação de desigualdade presente no país e para originar ações de branqueamento e higienismo, disseminadas durante o século XX e que tinham por objetivo resolver o problema da "mistura brasileira". Eis que, em tal contexto, entre os inúmeros livros e artigos publicados versando sobre o determinismo racial e sua utilização para explicar os fenômenos de caráter social, a publicação de A América Latina: Males de origem (1905) e A organização nacional (1914) soam como dissidentes, visto que os argumentos trazidos nestas obras não se articulam com o pensamento hegemônico da época.

Os livros são de autoria de Manoel Bomfim (1868 - 1932) e Alberto Torres (1865 - 1917), respectivamente, e trazem uma análise sobre o Brasil que despreza a explicação racialista, buscando propor uma saída para os problemas do país que diverge da ideia de branquear a população. Outros autores, que escreveram no mesmo período, também se propuseram a olhar o Brasil com desapego às teorias racialistas, como Paulo Prado (1869 - 1943), por exemplo, em O Retrato do Brasil (1928), mas que, ao contrário de Bomfim e Torres, não aponta saídas para aquela população que por algum motivo parecia avessa ao desenvolvimento. É por esta razão que estes dois autores foram escolhidos para compor o objeto deste trabalho: além de realizarem um diagnóstico da sociedade brasileira também sugerem um projeto para o Brasil-Nação.

\section{O Brasil-problema pelo viés das teorias racialistas}

Para Leite (2007), a supremacia do racismo durante o século XIX e início do XX está ligada a dois fatores principais: era uma das formas de justificar o domínio europeu (branco) sobre os demais povos, que seriam inferiores devido a determinantes naturais e biológicos, e estava em consonância com o pensamento evolucionista que, na época, conquistava diversos seguidores no velho mundo. As teorias evolucionistas enxergavam o mundo como um conjunto de sociedades inferiores, em estágios atrasados de desenvolvimento, que deveriam ser dominadas por outros grupos sociais aptos, situados em estágios de desenvolvimento avançados. A teoria da Seleção Natural de Darwin foi 
retirada da biologia para explicar os fenômenos sociais e fundamentar a ideologia racista que

Nunca foi uma verificação racional, nem uma tentativa de interpretar objetivamente a realidade; ao contrário, sempre teve o caráter de justificativa para as desigualdades entre classes e povos (LEITE, 2007, p. 39).

As teorias raciais que circulavam pela Europa chegaram ao Brasil e foram adaptadas ao contexto nacional para explicar principalmente os problemas do país e idealizar projetos que viabilizassem o Brasil-Nação. Assim, no Brasil, através das categorias de 'meio' e 'raça', estas teorias justificavam o atraso do país e permitiam pensar modos de evoluir até o "estágio" onde se encontravam as sociedades europeias. Além disso, com o fim da escravidão, as hierarquias então estabelecidas tornaram-se pauta de debates, o que acabou provocando a mobilização por novas organizações que preenchessem os espaços deixados pela dissolução da relação senhor/escravo (SCHWARCZ, 1993 apud COSTA, 2003).

Para os brancos, o negro, de inferior social na sociedade de castas, passava a inferior biológico na sociedade de classes. O 'preconceito' apareceu no novo contexto como uma técnica de ajustamento entre os grupos étnicos a partir do reconhecimento necessário e prévio da existência de desigualdades sociais, expressa sob a forma de desigualdades naturais (CARDOSO, 2011, p. 354, grifo do autor).

Este era o pensamento hegemônico da época e que tomava forma cientifica. No Brasil o discurso europeu foi sendo articulado por diversos intelectuais que consideravam as características fenótipas como determinantes das aptidões individuais, "as relações sociais se tornam variáveis derivadas da biologia" (COSTA, 2006, p. 153), esta última passando a ser definidora das hierarquias sociais então observáveis.

No Brasil, o pensamento racialista pode ser encontrado em Silvio Romero ${ }^{1}$, Nina Rodrigues $^{2}$, Euclides da Cunha $^{3}$, de forma mais leve (CANDIDO, 1990) em Joaquim Nabuco $^{4}$ e, estendendo-se até os anos 30, em Oliveira Vianna ${ }^{5}$. Segundo Costa (2006), estes autores dedicaram-se a analisar se os "não-brancos" eram inferiores, se a mestiçagem trazia efeitos negativos ou positivos à constituição da nacionalidade brasileira e se a evolução biológica, as características adquiridas pelos indivíduos ao

${ }^{1}$ Ver: DIMAS, Antonio. O turbulento e fecundo Silvio Romero. In: BOTELHO, André; SCHWARCZ, Lilia Moritz (orgs.). Um enigma chamado Brasil: 29 intérpretes e um país. São Paulo: Companhia das Letras, 2009.

${ }^{2}$ Ver: SCHWARCZ, Lilia Moritz. Nina Rodrigues: Um radical do pessimismo. In: BOTELHO, André; SCHWARCZ, Lilia Moritz (orgs.). Um enigma chamado Brasil: 29 intérpretes e um país. São Paulo: Companhia das Letras, 2009.

3 Ver: LIMA, Nísia Trintade. Euclides da Cunha: O Brasil como sertão. In: BOTELHO, André; SCHWARCZ, Lilia Moritz (orgs.). Um enigma chamado Brasil: 29 intérpretes e um país. São Paulo: Companhia das Letras, 2009.

${ }^{4}$ Ver: ALONSO, Angela. Joaquim Nabuco: O crítico penitente. In: BOTELHO, André; SCHWARCZ, Lilia Moritz (orgs.). Um enigma chamado Brasil: 29 intérpretes e um país. São Paulo: Companhia das Letras, 2009.

${ }^{5}$ Ver: GOMES, Angela de Castro. Oliveira Vianna: Um statemaker na alameda São Boaventura. In: BOTELHO, André; SCHWARCZ, Lilia Moritz (orgs.). Um enigma chamado Brasil: 29 intérpretes e um país. São Paulo: Companhia das Letras, 2009. 
longo da sua vida, eram passiveis de ser transmitidas pela hereditariedade, "com efeito, termos antropométricos e alusões a diferentes autores e métodos de medição craniométrica constituíam referências recorrentes utilizadas pelos 'homens de ciência' no Brasil" (COSTA, 2006, p. 157), destacando-se aí os estudos e medições realizados por Nina Rodrigues na Escola de Medicina da Bahia. Alusões também eram feitas aos aspectos ambientais e geográficos, capazes de determinar certas características aos indivíduos a eles submetidos, argumento que se encontra, por exemplo, em Os Sertões (1902) de Euclides da Cunha.

As análises nos moldes do racismo científico foram parte do surgimento das ações de branqueamento no Brasil. O branqueamento pode ser considerado como uma tentativa de "clarear" as características fenótipas da população não-branca e, de acordo com Domingues (2002, p. 566), "é uma das modalidades do racismo à brasileira". Segundo o autor, as ideias então difundidas de que os europeus eram superiores e de que a mestiçagem era degenerativa, deram início a uma imigração europeia com números consideráveis, objetivando "a absorção biológica do negro pelo branco" (DOMINGUES, 2002, p. 589). A iniciativa, no entanto, não possui apenas caráter biológico que, como supunham seus entusiastas, acabaria por erradicar o componente negro no Brasil. O outro lado da questão dizia respeito a um branqueamento moral e psicológico já que não bastava "clarear" a população, era necessário que esta se comportasse "como os brancos".

Ao assimilarem os valores sociais e/ou morais da ideologia do branqueamento, alguns negros avaliavam-se pelas representações negativas construídas pelos brancos. Era necessário ser um 'negro da essência da brancura'. Por isso, desenvolveram um terrível preconceito em relação às raízes da negritude (DOMINGUES, 2002, p. 576).

Assim, por exemplo, difundiu-se a ideia de que um negro ao casar-se com uma branca alcançaria uma melhora biológica, necessária para a então constituição de um Brasil-Nação. O negro, elemento discriminado, passa a ser reprodutor do discurso discriminatório colocando-o, então, enquanto um racista (DOMINGUES, 2002). Este comportamento pode ser notado em São Paulo, como relata Domingues (2002), e no sul, como relata Cardoso (2011, p. 333),

A ideia de branquidade e a caricatura da conduta pequeno-burguesa dos brancos generalizavam-se entre os negros capazes de reagir as próprias condições de vida, quase desaparecendo as reivindicações da negritude. Constituiu-se assim um novo momento da alienação do homem negro.

Como mencionado, o discurso do racismo científico difunde-se no Brasil até a terceira década do século $\mathrm{XX}$, sendo que só duas exceções parecem ter importância neste cenário (COSTA, 2006), os trabalhos de Manoel Bomfim e Alberto Torres, responsáveis por emergir neste momento teses anti-racialistas que explicavam o Brasil pela sua composição histórica, política e social, desconsiderando as classificações biológicas. 


\section{Rompendo paradigmas}

Em palestra realizada no Instituto de Estudos Avançados, Antonio Candido (1990) fala sobre o radicalismo no Brasil, ou seja, "o conjunto de ideias e atitudes formando contrapeso ao movimento conservador que sempre predominou" (CANDIDO, 1990, p. 4). Para ele o radical típico-ideal é aquele que pensa os problemas do país e propõe soluções para os mesmos buscando harmonia e conciliação e não a revolução, mesmo que seu pensamento chegue a aproximar-se do revolucionário, como é o caso de Bomfim. Por enfrentar o conservadorismo, suas ideias podem, no máximo, "ser ouvidas" e mesmo que implementadas não o serão em sua forma original.

Candido faz uma associação entre classe e radicalismo, sendo que este estaria relacionado às classes médias, o que não impede, no entanto, que indivíduos pertencentes à elite tenham "surtos" radicais que ocasionem a tomada de medidas progressistas. É assim que Candido define Alberto Torres, pois teria realizado um rompimento com o conservadorismo ao excluir o fator "raça" da explicação dos problemas brasileiros. Bomfim, ao contrário, é tomado por ele enquanto um radical permanente porque "analisou com dureza, além do regime de trabalho, as bases da sociedade brasileira e latino-americana" (CANDIDO, 1990, p. 10), um dos "pensadores mais originais e clarividentes que o Brasil teve em relação a problemas que no seu tempo eram propostos e estudados de maneira insatisfatória" (CANDIDO, 1990, p. 10).

Antes de adentrar no pensamento de Bomfim e Torres é necessário justificar a escolha destes dois autores para compor o objeto do presente trabalho. Como mencionado, seus contemporâneos eram adeptos ao elemento "raça" para explicar os fenômenos sociais, no entanto, Bomfim e Torres não eram os únicos a questionar este pensamento. Joaquim Nabuco (1849 - 1910), por exemplo, em O Abolicionismo (1882), indica que a escravidão é a responsável pelo atraso político, econômico e social do país, pois, enquanto instituição, estrutura todos os costumes e práticas da sociedade brasileira (ALONSO, 2009). Para ele, o regime escravocrata é ilegal e ilegítimo, incompatível com a modernização que a elite brasileira almejava. Assim, engaja-se no movimento abolicionista do país, buscando reformas que acabassem com os males da escravidão. Consciente de que esta se enraizou na cultura do Brasil de forma profunda, Nabuco acredita que seus malefícios só serão realmente eliminados, e não mais perpetuados, a partir do desenvolvimento de uma nova sociedade mediante a "instituição da pequena propriedade e a atração de imigrantes europeus de classe média” (ALONSO, 2009, p.64).

Para ele a abolição seria apenas o começo de uma grande reforma social, porque deveria criar condições para o escravo se tornar cidadão pleno, a fim de que a sociedade mestiça e plurirracial assumisse a sua realidade. Só o povo, assim concebido e atuando na sua totalidade, livre da tirania das classes dominantes, poderia realizar o nosso destino histórico (CANDIDO, 1990, p. 8).

Assim, num primeiro momento, Nabuco também produz uma ruptura com o pensamento da época ao explicar os problemas brasileiros por fatores econômicos, políticos e excluindo os raciais. No entanto, "às vezes resvala para juízos sobre a inferioridade de negros e chineses" (CANDIDO, 1990, p. 64-65), com relação aos últimos, se posiciona totalmente contra sua vinda para o país enquanto mão-de-obra e 
para justificar sua postura vale-se das teorias de "superioridade das raças". Mesmo que não encontre no negro o responsável pelo atraso do país, Nabuco acredita que com a vinda de imigrantes europeus, o sangue negro se dissolveria, incorporando-se ao caucásio, considerado superior.

Para Candido (1990), Nabuco é um radical temporário. Não menospreza sua importância em perceber "de maneira talvez única naquele momento qual era a condição do trabalhador e, como decorrência, qual era a natureza verdadeira do povo brasileiro" (CANDIDO, 1990, p. 7) e considera seus traços de racismo inevitáveis devido ao peso que tal pensamento possuía na época. Como afirma Candido, posicionar-se contra a vinda de imigrantes chineses para o Brasil não era em Nabuco uma manifestação do racismo, mas uma maneira de impedir esta "mentalidade que procurava extrapolar o sistema escravista e estender as suas características a todo trabalhador, considerado como máquina humana à disposição integral do senhor, ou do patrão" (CANDIDO, 1990, p. 7).

No entanto, por afiliar-se às ideais do pan-namericanismo, Nabuco deixa de ser tomado por Candido enquanto um radical, por isso do termo "temporário".

Nabuco se entusiasmou por isso, como se fosse a solução para o Brasil e todo o subcontinente, segundo a mesma ótica de Rio Branco, Rui Barbosa e outros. O radical de 1883 não percebeu, nos últimos dez anos de vida, que o imperialismo norte-americano era tão grave no plano externo quanto fora a escravidão no plano interno (CANDIDO, 1990, p. 9).

Assim Nabuco não pode ser tomado como objeto deste trabalho. Mesmo que tenha rompido com alguns pressupostos científicos da sua época, mantém uma relação ambígua com o tema das raças e é adepto ao americanismo, criticado por Bomfim e Torres. Paulo Prado (1869 - 1943), em O Retrato do Brasil (1928), empreende uma crítica ao "estrangeirismo" como um dos fatores que obstrai o progresso do país. Não só por esta razão o autor aproxima-se de Bomfim e Torres, pois também associava os problemas do Brasil à colonização e ao imperialismo e desconsiderava atribuir fatores negativos aos negros e mestiços. Para Prado, a colonização deixou de herança para a sociedade brasileira um conjunto de males (luxúria, cobiça e tristeza) responsáveis por constituir aqui uma sociedade amorfa ou "atrofiada", para usarmos os termos de Bomfim. Mesmo considerando a revolução como uma possível saída para esta situação, acreditava ser esta muito difícil, visto que o povo e a elite eram muito ignorantes. Não traz nenhum projeto para o Brasil-Nação, portanto, também é excluído como objeto deste trabalho. Como mencionado, Bomfim e Torres são escolhidos por possuírem algumas características em comum: realizam um diagnóstico da sociedade brasileira e apontam um projeto para o Brasil-Nação que só torna-se possível mediante o protagonismo do Estado, além disso, rompem com o pensamento evolucionista da época ao desconsiderarem o fator raça para explicar o suposto atraso brasileiro, que teria suas origens na colonização portuguesa aqui estabelecida.

Manoel Bomfim, sergipano e médico de formação, além de dedicar-se à análise da situação brasileira, também desenvolveu vários trabalhos na área da educação (alguns juntamente com Olavo Bilac). Viaja à Paris para estudar psicologia e pedagogia, em 1901, e, alguns anos depois, dedica-se a escrever seu mais famoso livro, A América 
latina (1905). O médico sempre defendeu a disseminação da educação básica, de alcance popular, acreditando que através dela fosse possível reverter o quadro de atraso vivido pelos países sul-americanos.

No livro, o autor faz uso de uma linguagem naturalista, explicando a sociedade pelo viés biológico, comparando-a a um organismo vivo e indicando que os fenômenos sociais estão imbricados em leis gerais de funcionamento. Não descarta a ideia do evolucionismo, frisando que sim, as sociedades humanas caminham para o progresso. Esta rápida caracterização poderia enquadrá-lo no então conjunto de pensadores positivistas, evolucionistas e racistas. Sua originalidade, no entanto, está em pensar os "desvios de progresso" sofridos por algumas sociedades pelo viés da constituição histórica e não biológica, com a qual se identificava o pensamento dominante da época.

Para Bomfim, o problema da América Latina era o parasitismo social, considerado uma "doença" responsável pelos seus obstáculos e atraso. A análise não se centra, porém, apenas nos indivíduos parasitados, mas mostra como as nações ibéricas, colonizadoras do continente, são também vítimas do parasitismo, tendo, como os povos latinos, seu desenvolvimento estagnado, "uma sociedade que viva parasitariamente sobre outra perde o hábito de lutar contra a natureza; não sente necessidade de apurar os seus processos, nem de pôr em contribuição a inteligência" (BOMFIM, 1905, p. 25). Para Bomfim, é este processo que se desenvolve na América Latina, foi "parasitada", "sugada", fato que reduziu a marcha do seu desenvolvimento, em relação a outros povos. Espanha e Portugal, no entanto, que apostaram na exploração enquanto desenvolvimento, viram o tiro sair pela culatra, acomodaram-se, atrofiaram seu percurso ao progresso e, neste sentido, padecem dos mesmos males latino-americanos.

A dominação sobre os povos latinos era vista num primeiro momento como parasitismo heroico, um período de destruição, "conquistas" territoriais. Passado este período, Bomfim identifica a instalação do sedentarismo, iniciando-se o processo de degeneração dos povos. Portugal e Espanha não mais invadiam e trucidavam, o parasitismo propagou-se pelas colônias instalando-se em todas as esferas da vida. $\mathrm{O}$ objetivo passa a ser extorquir "cerravam os olhos e tapavam os ouvidos ao progresso científico, aferravam-se a esse viver que lhes parecia o ideal - sugar! sugar! sugar!" (BOMFIM, 1905, p. 80). Mesmo assim, Bomfim não nega que os maiores afetados pelo regime parasita são os próprios povos invadidos, que no caso latino americano, foram enfraquecidos, violentados para obrigarem-se a manter o parasita "vivo" e adaptados a um modo de vida novo, estranho.

O quadro de consequências do parasitismo tem para Bomfim um quádruplo aspecto: político, econômico, social e moral. $\mathrm{O}$ autor enfatiza que a escravidão refletiuse no comportamento político destes estados-nação sendo o estado um instrumento nas mãos da elite e explorando a população juntamente com esta, "se achava em oposição aos interesses reais das novas populações, e não podia servir nem mesmo como ponto de partida para uma organização política definitiva" (BOMFIM, 1905, p. 103). Neste sentido, atua como conservador da máquina estatal dedicando pouca ou nenhuma atenção às questões de utilidade pública, o que, em suma, deveria ser sua função. Em relação ao nível social, moral e intelectual, o regime surtiu efeitos quanto à constituição de grupos heterogêneos, distintos, desunidos que passaram a viver em conflito. Para o autor isto produziu uma "perversão do senso moral, horror ao trabalho livre e à vida 
pacífica, ódio ao governo, desconfiança das autoridades, desenvolvimento dos instintos agressivos" (BOMFIM, 1905, p. 110).

A transmissão destas características e a reprodução do parasitismo se dão por meio da hereditariedade social: "em que consiste a hereditariedade social? Consiste na transmissão, por herança, das qualidades psicológicas, comuns e constantes, e que, [...] dão a cada grupo social um caráter próprio distintivo" (BOMFIM, 1905, p. 112). Para Bomfim, assim como caracteres físicos e biológicos são transmitidos pela hereditariedade, com os traços psicológicos e costumes procede-se da mesma maneira. Mais uma vez não parece o autor entender a sociedade enquanto um organismo, mas sim fazer uso de tal analogia para auxiliá-lo em suas análises. O autor também empreende uma forte crítica ao descaso com a educação básica, o que mantém a massa populacional analfabeta e que, no entanto, conserva um punhado de doutores que nada tem a contribuir, visto que a população sequer está habilitada para entender sobre o que falam.

Posteriormente, Bomfim empreende uma crítica ao modo de enxergar o Brasil pelo modelo da análise racial. Fala sobre a "Teoria científica do valor das raças", considerando-a como uma justificativa para a opressão dos fracos pelos fortes, "de acordo com esses princípios, os indígenas americanos, os pretos africanos, os negroides e malaios da Oceania, foram declarados 'inferiores', em massa" (BOMFIM, 1905, p. 193, grifo do autor). Critica também o mau uso feito da teoria da Seleção Natural de Darwin que serve como base para estas concepções que se apresentam sobre dois argumentos principais: (I) a constante eliminação de índios e negros prova sua inferioridade e (II) estes são muito atrasados em relação aos europeus, visto que vivem em estado de selvageria e barbárie. Bomfim também desacredita nos ditos "efeitos regressivos da mestiçagem" justificando que os males da América Latina são decorrentes de sua organização política e econômica e não de fatores biológicos e raciais.

Como mencionado, para Candido (1990), Bomfim era um radical permanente. Não se chega aqui a este ponto, de qualificá-lo ou não enquanto um radical, mas de evidenciá-lo enquanto um autor que propõe um duplo rompimento com a ciência da época, utiliza uma forma e retórica analítica tão incomum: pensar os contextos atuais em relação às configurações anteriores, históricas, articulando o local e o global, e redigindo isto com uma linguagem literária, irônica, apaixonada, até mesmo parcial, algo oposto à escrita científica. Acredita-se ser essa sua grande contribuição para pensar o Brasil, romper com as teorias então estabelecidas, inserindo elementos novos no debate sobre o caráter nacional e proporcionando que o problema seja pensado por outros ângulos, a partir de um viés mais otimista, e principalmente, de forma autêntica: compreender a sociedade pelas relações e conexões sociais então estabelecidas.

Alberto Torres era bacharel em direito e preocupado com a questão da unidade e organização nacional. Torres também desconsidera a questão da raça para pensar os problemas brasileiros associando estes a desorganização política e social do país. Esta análise do autor está exposta em A Organização nacional (1914), onde defende uma reforma constitucional para redefinirem-se os interesses e projetos do Brasil (KUNTZ, 2002).

Torres foi presidente do estado do Rio de Janeiro (1897 - 1900) e ministro do Supremo Tribunal Federal (1901 - 1907). É necessário observar que era um entusiasta 
republicano desiludido com a então recente instauração da República, relacionando a ela boa parte da falta de organização no país. Torres evidencia o caráter geográfico do Brasil como um dos responsáveis pelo caos: o colonizador não se adaptou ao clima e a "terra" que aqui encontraram, o que ocasionou a desorganização também associada à falta de consciência política dos brasileiros,

Deste estado de desencontro, de ignorância e de conflito, entre a terra e seus habitantes, entre as raças e o meio cósmico, e entre as raças, o meio, as instituições, os costumes e as ideias, resultam os traços que formam o relevo convulsionado da nossa estrutura nacional (TORRES, 1915, p. 12).

Em O Problema nacional brasileiro (1914), Torres associa os problemas do país à colonização, assim como Bomfim. Indica que "governos coloniais e colonizadores fazem invasões e conquistas: não fundam nações; são exploradores, não são sócios" (TORRES, 1914b, p. 77), ou seja, Portugal não estava preocupado em transformar o Brasil em um país, sendo este, portanto, "um improviso social do acaso" (TORRES, 1914b, p. 77). Suas explanações parecem mostrar que também associa o início dos problemas brasileiros à exploração praticada por Portugal, que teria sufocado a constituição da nacionalidade e produzido um país sem espírito e unidade. A saída para Torres está em traçar uma política para o país, o que só é possível despertando-se a consciência política do povo.

Ao mencionar que "o homem moderno resulta, muito mais diretamente, do meio que habita, e, principalmente, da sociedade que o cerca, que dos impulsos congênitos de sua estirpe (TORRES, 1914b, p. 54), Torres está vinculando os problemas do Brasil a fatores geográficos e sociais, realizando um rompimento com a ciência da época que frisava o papel da "raça" no desenvolvimento, "a verdade é que não existindo um caráter próprio destes ou daqueles grupos humanos, senão caracteres relativos às condições, locais ou ocasionais, da sua origem, da sua passagem, ou da sua existência" (TORRES, 1915, p. 9). Critica também o estado, por desconhecer sua população, sua natureza, suas possibilidades, e o "estrangeirismo" que importa tudo e analisa o Brasil pelos olhos dos outros, o país tem mais que respeito, tem "superstição pelo valor do estrangeiro e submissão à sua autoridade" (TORRES, 1915, p. 33). Como um bom nacionalista, se posiciona contra a imigração de estrangeiros enquanto mão-de-obra e defende os empreendimentos nacionais e a educação dos ex-escravos a fim de profissionalizarem-se e estarem aptos ao trabalho.

Ao tentar analisar pontos em comum entre Manoel Bomfim e Alberto Torres se está, como mencionado, diante de dois pensadores que enxergam os problemas do Brasil como decorrentes do seu desenvolvimento histórico, principalmente com relação à colonização portuguesa. Os dois, inclusive, empreendem uma crítica aos portugueses ao tratá-los como desinteressados pelo trabalho e orientados apenas para a exploração. Bomfim associa o desinteresse dos ibéricos pelo trabalho a causas relacionadas ao seu desenvolvimento histórico, marcado por inúmeras batalhas e guerras. Ele se pergunta "Qual o efeito destes onze séculos de guerra constante e generalizada sobre o caráter das nacionalidades ibéricas? De que forma esse passado vem influir sobre o futuro?" (BOMFIM, 1905, p. 38). As consequências giram em torno do desenvolvimento de um modo de vida baseado em saques, depredações e impossibilidade de adaptação a uma 
conduta pacífica, originando a "perversão do heroísmo" que tornou o trabalho repugnante e as formas fáceis de ganhar a vida, prazerosas, "porque se habituara a viver exclusivamente do fruto das conquistas; porque não sabia fazer outra coisa senão guerrear (BOMFIM, 1905, p. 43)".

Em As fontes de vida no Brasil (1915), Alberto Torres argumenta que no Brasil se produzem apenas ociosos, já que "nunca fundamos no país coisa nenhuma própria a criar o interesse pelo trabalho, entre os homens do povo" (TORRES, 1915, p. 32). Aproximando-se das análises de Bomfim, ele escreve que "o impulso que nasceu com o bandeirante, com o desbravador de florestas, [...] perpetuou-se pela história adiante, firmando as normas da aventura e do saque à natureza, como estímulo à ação do homem sobre a terra" (Ibid., p. 38). A ausência de um regime social do trabalho, somada a falta de adaptação do colono a terra, coloca o Brasil numa situação de desorganização, tornando-o uma "sucessão de povos" com a inexistência de sentimento de nacionalidade, uma ligação entre os indivíduos. Para ele, a função da sua geração é "restaurar as fontes da vida, no corpo do país, e as fontes da vida, no corpo e no espírito de seus habitantes; aquelas, pelo clima, e, sobretudo, pela água; e esta pelo trabalho" (TORRES, 1915, p. 53).

\section{O protagonismo do Estado no projeto do Brasil-Nação}

É comum a Manoel Bomfim e Alberto Torres a ausência das teorias raciais para analisar o Brasil. Poder-se-ia enquadrar diversos outros autores nesta caracterização, não fosse pelo fato de Bomfim e Torres estarem escrevendo em uma época onde tais ideias não são bem aceitas e de suas análises serem propositivas, lançam-se a traçar um projeto que viabilizasse o "Brasil-Nação".

Iniciemos por Bomfim. Já está explicitado o diagnóstico de Bomfim sobre o Brasil e a América Latina: possuem uma doença, o parasitismo social, resta saber os apontamentos do autor com relação "a cura". Já foi evidenciado que Bomfim empreende uma crítica ao conservadorismo às elites e posiciona-se contra $o$ estrangeirismo, já que, segundo ele, a mão do estrangeiro nunca é "inocente", sempre carrega consigo o desejo de exploração. Neste sentido, desacredita que as soluções para os problemas nacionais decorram tanto das elites como de outros países, necessita vir de dentro, do povo, por isso é tomado por muitos como um revolucionário. A cura está na instrução escolar, na erradicação do analfabetismo mediante a difusão da educação básica, diz ele: "façamos a campanha contra a ignorância" (BOMFIM, 1905, p. 271). Para Bomfim, a razão do atraso de alguns países está ligada à falta de conhecimento que tem de si próprios, de seus problemas. Ao falar do conservadorismo, como um dos produtos do parasitismo que a tudo estagna, o autor pontua a falta de interesse que os latinos têm pelo conhecimento, pela descoberta. Assim, seu projeto para o país, evidenciando a necessidade da educação para reverter seus problemas, tem um aspecto de cidadania "a própria inteligência cria para si necessidades" (BOMFIM, 1905, p. 276). Ele entende que, conhecendo seus problemas, os indivíduos buscam meios de solucioná-los, e assim instaura-se a necessidade de descobrir coisas novas, sanar novas demandas. Este é o ritmo para o progresso. 
Alberto Torres, ao contrário de Bomfim, é mais ambicioso, pois traça uma verdadeira reforma política através da qual seria, então, possível colocar o Brasil no rumo do desenvolvimento. Assim como a educação representa em Bomfim a liberdade e a emancipação, em Torres é a política que ocupa este papel. Suas orientações para o projeto de "Brasil-Nação" dizem respeito a uma nova forma de ocupação territorial, menos destruidora, com o incentivo à pequena propriedade, resistir à tendência expansiva do capital e instaurar uma reforma constitucional no país (KUNTZ, 2002). Para que isso se concretize, Torres enfatiza a necessidade de um poder público central e efetivo reduzindo a autonomia provincial.

Os poderes atribuídos à União se destinam a construir a ordem econômica e social imaginada por Torres - um país fiel à sua suposta vocação agrícola, capaz de produzir com eficiência, menos vulnerável às turbulências internacionais e a ganância do capital estrangeiro, livre dos defeitos do coletivismo e do individualismo extremado e justo na distribuição de oportunidades a todas as pessoas (KUNTZ, 2002, p. 272).

Torres propõe a criação de um Poder Coordenador, capaz de integrar as instituições nacionais e realizar a soberania da lei, da igualdade, da democracia. Nesse sentido é um poder central forte e capaz de unir todos os órgãos governamentais para a real condução do país ao progresso. "As ideias do projeto aqui desenvolvido são destinadas a corrigir os defeitos do regime democrático e a indicar os meios de o adaptar, bem como o regime federativo, à nossa terra e ao nosso povo" (TORRES, 1914a, p. 425). O Poder Coordenador seria o responsável por organizar o Brasil, tornar real a unidade nacional e assegurar, ao mesmo tempo, as liberdades individuais.

Para os dois autores apresentados, o Estado desempenha um papel fundamental nestas reformas: quanto ao primeiro, em levar educação a todos, quanto ao segundo, promovendo uma reforma constitucional. É claro que a função estatal fica mais evidente no projeto de Torres já que é a própria reforma do Estado, um novo governo para instaurar uma sociedade. No entanto, deve-se lembrar, que um projeto como o de Bomfim é tão pretensioso quanto o outro, no caso, é lutar contra a elite e o conservadorismo. Eles são o Estado, logo é necessária uma mudança também a nível governamental, ou tudo isso se torna inviável.

Talvez os dois, no entanto, não tenham imaginado a dimensão disso e a provável possibilidade de perder-se no tempo como uma utopia. Por isso, por muitos, Bomfim é lembrado como um revolucionário e Torres como um autoritário. De certa forma, os dois eram reformadores, um pelo viés educacional, outro pelo viés político, mas nos dois projetos, o estado desempenha um papel importante, conduz a execução destes. Mesmo com projetos divergentes, suas análises são muito próximas, e o país que almejam, parece ser o mesmo: unido, conhecedor de si e capaz de buscar aquilo que almeja. Mas para isso é preciso "organizar" o país e "difundir" a educação, as duas ideias parecem assimilar-se. 


\section{Considerações finais}

Outra aproximação interessante entre Bomfim e Torres é a de que os dois só terão suas obras reconhecidas depois de um bom tempo de escritas. Bomfim cai num esquecimento por várias décadas, vindo a ser lembrado por Darcy Ribeiro como "o grande intérprete do processo de formação do povo brasileiro" (RIBEIRO, 1993, apud CANDIDO, 1990), Torres, porém, é recuperado já na década de 30, principalmente por Oliveira Vianna, engajado politicamente no Governo Vargas. Nos anos 30, Vianna utiliza Torres para fundamentar suas propostas para a solução dos problemas brasileiros, "da formulação de diagnósticos dos problemas do país, passa a se dedicar à implementação de políticas públicas que visavam enfrentá-los, pela via da intervenção de um Estado autoritário, de tipo corporativo" (GOMES, 2009, p. 150).

É então que Alberto Torres passa a ser conhecido, por intermédio dos estudos de Vianna, colocando o autor numa posição de autoritário. Torres faz, certamente, uma forte defesa a um Estado forte, unificador, no entanto não deixa de frisar a necessidade do mesmo conciliar à isso a liberdade individual. Ao contrário de Torres, Vianna faz uso das teorias racialistas para explicar o atraso político e social do Brasil, e assim retoma o outro autor fazendo jus à suas análises da realidade brasileira, evidenciando o problema político-organizacional, a falta de solidariedade, a influência que o meio físico pode exercer sobre as sociedades e a necessidade de um Estado autoritário para por o país no ritmo do progresso, adicionando a isso argumentos racistas (BRANDÃO, 2002).

As razões que explicam o esquecimento de Bomfim e Torres são várias. Quanto à Bomfim podem-se falar da utilização da analogia com o mundo biológico, sua escrita desapegada do "cienticismo" e seu romantismo. Para Oliveira Vianna (OLIVEIRA VIANNA, 1987 apud PINHO, 2007), Torres não se tornou consagrado a seu tempo devido à sua negação ao estrangeirismo, "Torres nunca se apoiava em ninguém, nunca citava autores estrangeiros, limitando suas leituras a uma biblioteca reduzidíssima, [...] mas que [...] não aparecia nos seus livros" (OLIVEIRA VIANNA, 1987 apud PINHO, 2007, p. 118). Mas algo parece ser comum aos dois, pensavam fora de seu tempo. Isso quer dizer que não despertavam o interesse porque suas obras estavam desconectadas do contexto em que escreviam e, por isso, só são retomadas mais tarde, quando passam a apresentar pontos interessantes.

Como mencionado, em relação ao inicio do século XX, Bomfim e Torres soam como dissidentes, pois, ao contrário da maior parte dos seus contemporâneos, não associam os problemas do Brasil à existência de raças inferiores ou à miscigenação, pelo contrário, relacionam-nos a fatores históricos, políticos e econômicos, a colonização portuguesa principalmente. Na época, isto os coloca numa posição marginal não despertando a atenção do público já que o pensamento hegemônico girava em torno das teorias racialistas, dos determinismos biológicos e raciais. Além disso, os dois se propõem a criticar a elite brasileira e o estrangeirismo, também responsáveis pela perpetuação dos problemas do país.

O pensamento de Bomfim e Torres entra para o cenário nacional, principalmente, pela originalidade ao tratar o "Brasil-Problema" desconectando-se dos seus contemporâneos ao refletir o país pelo viés sócio-histórico. De alguma forma, suas análises são posteriormente retomadas por outros autores que tornaram a frisar a 
ausência de raças inferiores ou de malefícios ligados à miscigenação e a necessidade de pensar estes problemas, não pelo viés biológico, mas sim sociológico.

\section{Referências:}

ALONSO, A. Joaquim Nabuco: O crítico penitente. In: BOTELHO, A.; SCHWARCZ, L. M. (orgs.). Um enigma chamado Brasil: 29 intérpretes e um país. São Paulo: Companhia das Letras, 2009.

BOMFIM, M. América Latina: Males de origem. Rio de Janeiro: Centro Edelstein de Pesquisas Sociais, 1905/2008.

BRANDÃO, G. M. Oliveira Vianna - Populações Meridionais do Brasil. In: CANDIDO, A. Radicalismos. Estudos Avançados. Abril de 1990. Vol. 4, n. 8, pp. 418.

CARDOSO, F. H. Capitalismo e escravidão no Brasil Meridional: O negro na sociedade escravocrata do Rio Grande do Sul. Rio de Janeiro: Civilização Brasileira, 2011.

COSTA, J. C. de C. Nação, raça e miscigenação no Brasil moderno: Uma análise hermenêutica dos Ensaístas da formação da nacionalidade brasileira, 1888-1928. Tese (Doutorado em Sociologia) - Programa de Pós-Graduação em Sociologia da Universidade Federal de Pernambuco. Recife, 2003.

COSTA, S. Dois atlânticos: Teoria social, anti-racismo, cosmopolitismo. Belo Horizonte: Editora da UFMG, 2006.

DOMINGUES, P. J. Negros de Almas Brancas? A Ideologia do Branqueamento no Interior da Comunidade Negra em São Paulo, 1915-1930. Estudos Afro-Asiáticos, 2002, Ano 24, n. 3, p. $563-599$.

GOMES, A. de C. Oliveira Vianna: Um statemaker na alameda São Boaventura. In: BOTELHO, A.; SCHWARCZ, L. M. (orgs.). Um enigma chamado Brasil: 29 intérpretes e um país. São Paulo: Companhia das Letras, 2009.

KUNTZ, R. Alberto Torres - A Organização Nacional. In: DANTAS, L. Um Banquete no Trópico: Introdução ao Brasil, vol. 2. São Paulo: Editora SENAC São Paulo, 2002.

LEITE, D. M . O caráter nacional brasileiro: História de uma ideologia. São Paulo: Editora UNESP, 2007.

PINHO, S. O. C. de. Alberto Torres: Uma obra, várias leituras. Dissertação (Mestrado em História) - Programa de Pós-Graduação em História da Universidade Federal de Minas Gerais. Belo Horizonte, 2007.

TORRES, A. A organização nacional. EBooksBrasil - Digitalização da Versão Impressa: $1914 \mathrm{a} / 2002$.

TORRES, A. As fontes de vida no Brasil. EBooksBrasil - Digitalização da Versão Impressa: Rio de Janeiro, 1915/2001.

TORRES, A. O problema nacional brasileiro. EBooksBrasil - Digitalização da Versão Impressa: 1914b/2002. 